\title{
THE PROCESS OF EMPOWERMENT: IMPLICATIONS FOR THEORY AND PRACTICE
}

\author{
JOHN LORD \\ Centre for Research and Education in Human Services \\ and \\ PEGGY HUTCHISON \\ Brock University
}

\begin{abstract}
This article describes a research study completed on the process of empowerment. Conducted with 55 men and women who had experienced extensive powerlessness in their lives, qualitative interviews and focus groups were designed to understand participants' lived experiences as they struggled loward increased control in their lives. Several themes were identified, including elements which provided an impetus for empowerment and the importance of support from people. As the empowerment process unfolded, access to valued resources and participation in community life reduced isolation and contributed to the competence and confidence of participants. Several implications for the concept of empowerment are identified such as selfefficacy and personal control; and principles for community practice are outlined. This study confirms the importance of understanding empowerment from an ecological perspective.
\end{abstract}

\section{INTRODUCTION}

The concept of empowerment is of increasing interest to researchers, practitioners and citizens concerned about mental health issues. In some respects, empowerment is a new buzzword. As Edelman (1977) has noted in relation to language and the politics of human services, sometimes new language is used to describe the same old practices, Others believe that empowerment language can actually lead to raised awareness (Rappaport, 1986). Regardless, a growing number of people are searching to understand the meaning of empowerment and ways it can be used to change their settings and lives.

Empowerment can begin to be understood by examining the concepts of power and powerlessness (Moscovitch \& Drover, 1981). Power is defined by the Cornell Empowerment Group as the "capacity of some persons and organizations to produce intended, foreseen and unforeseen effects on others" (1989,

Both authors are involved in the Empowerment Research Project at the Centre for Research and Educa: tion in Human Services. This ongoing research bas been partially funded by the Secretary of State, Government of Canada, and the Scottish Rite Foundation. This article is based on a series of empowerment studies completed at the Centre, Some of these dats have also been published as Lives in Transition. The Process of Personal Empowerment, a monograph which is avallable from the Centre (P.O. Box 3036. Stn. C, Kitchener, ON N2G 4R5). 
p. 2). There are many sources of power. Personality, property/wealth, and influential organizations have been identified by Galbraith (1983) as critical sources of power in the last part of this century. Others have pointed out that the classdominated nature of our society means that a small number of people have vast economic or political power, while the majority have little or none (Moscovitch \& Drover, 1981).

At the individual level, powerlessness can be seen as the expectation of the person that his or her own actions will be ineffective in influencing the outcome of life events (Kieffer, 1984). Lerner (1986) makes a distinction between real and surplus powerlessness. Real powerlessness results from economic inequities and oppressive control exercised by systems and other people. Surplus powerlessness, on the other hand, is an internalized belief that change cannot occur, a belief which results in apathy and an unwillingness of the person to struggle for more control and influence. Powerlessness has, over the years, come to be viewed as an objective phenomenon, where people with little or no political and economic power lack the means to gain greater control and resources in their lives (Albee, 1981). As an illustration of powerlessness, Asch (1986) has noted that generally people with disabilities;

... have so internalized the general negative attitudes towards them because of their disabilities that they cannot believe that collective action can improve their lives. They have seen the problems as inherent in their medical conditions and have not been urged to join others to demand structural changes that would render the environment useful for them (p. 13).

Most of the literature also associates empowerment with personal control. Rappaport (1987) points out that "by empowerment I mean our aim should be to enhance the possibilities for people to control their own lives" (p. 119). Cochran (1986) believes that people understand their own needs far better than anyone else and as a result should have the power both to define and act upon them. The Ottawa Charter for Health Promotion notes that "people cannot achieve their fullest health potential unless they are able to take control of those things which determine their health" (World Health Organization, Health and Welfare Canada, \& Canadian Public Health Organization, 1986, p. 1).

Increasingly, empowerment is being understood as a process of change (Cornell Empowerment Group, 1989). McClelland (1975) has suggested that in order for people to take power, they need to gain information about themselves and their environment and be willing to identify and work with others for change. In a similar vein, Whitmore (1988) defines empowerment as:

an interactive process through which people experience personal and social change, enabling them to take action to achieve influence over the organizations and institutions which affect their lives and the communities in which they live (p. 13).

Kieffer's (1984) work on personal empowerment is one of the only major empirical studies which examines personal empowerment as a process. He labels empowerment as a developmental process which includes four stages: entry, advancement, incorporation, and commitment. The entry stage appears to be motivated by the participant's experience of some event or condition threatening to the self or family, what Kieffer refers to as an act of "provocation." In the ad- 
vancement stage, there are three major aspects which are important to continuing the empowerment process: a mentoring relationship, supportive peer relationships with a collective organization, and the development of a more critical understanding of social and political relations. The central focus of the third stage appears to be the development of a growing political consciousness. Commitment is the final stage-one in which the participants apply the new participatory competence to ever expanding areas of their lives.

According to Wallerstein (1992), empowerment is a social-action process that promotes participation of people, organizations, and communities toward the goals of increased individual and community control, political efficacy, improved quality of community life, and social justice. While Whitmore (1988) feels the concept of empowerment needs to be more clearly defined, she states that there are some common underlying assumptions: (a) individuals are assumed to understand their own needs better than anyone else and therefore should have the power both to define and act upon them, (b) all people possess strengths upon which they can build, (c) empowerment is a lifelong endeavour, (d) personal knowledge and experience are valid and useful in coping effectively. For the purpose of this study, empowerment was defined as processes whereby individuals achieve increasing control of various aspects of their lives and participate in the community with dignity.

Rappaport's (1987) concept of empowerment, "conveys both a psychological sense of personal control or influence and a concern with actual social influence, political power and legal rights" (p. 121). In this sense, empowerment can exist at three levels: at the personal level, where empowerment is the experience of gaining increasing control and influence in daily life and community participation (Kieffer, 1984); at the small group level, where empowerment involves the shared experience, analysis, and influence of groups on their own efforts (Presby, Wandersman, Florin, Rich, \& Chavis, 1990); and at the community level, where empowerment revolves around the utilization of resources and strategies to enhance community control (Labonté, 1989).

While this current study was focused primarily on the personal level, it is important to note that it is difficult to clearly separate the three levels of empowerment; indeed, the three levels are highly interactive. Understanding individual change and empowerment informs community empowerment strategies and policy and vice versa. As a result, it is important that research on empowerment begin with an understanding of individuals, not in a clinical sense, but in an experiential sense (Lord, 1991). This means that understanding empowerment is complex and ecological. This study on empowerment looked at the "person in the environment" by trying to understand the lived experience of citizens in relation to family, groups, and other aspects of community life.

\section{PURPOSE OF THE RESEARCH}

The purpose of the research was to understand the process of personal empowerment as experienced by individuals who were currently involved in the struggle to become empowered. Specifically, the goals of the study were to: (a) document the participants' early and current experiences of devaluation and 
powerlessness in their personal, social, and community lives; (b) explore the transition from powerlessness to empowerment, including personal qualities, experiences, and elements which people indicated were helpful to them as they gained more control and increased participation in their lives, and (c) analyze the meaning of people's life experiences, both of powerlessness and the empowerment process.

\section{METHODS}

Forty-one men and women who had experienced extensive powerlessness in their lives were selected as the research participants. Using qualitative interviews, this study was designed to understand participants' lived experience "from their own point of view," as they struggled to reduce personal powerlessness and dependency. This qualitative approach (Guba \& Lincoln, 1989; Lord, Schnarr, \& Hutchison, 1987; Patton, 1990) has provided an in-depth examination of the process of people's transition toward increased control in their lives.

The research team used four main approaches to study the process of personal empowerment: an extensive literature review, interviews with a number of key informants, in-depth biographical interviews with people who had experienced extensive powerlessness in their lives, and focused group interviews in order to gain further reflections on the initial findings from the biographical interviews (de Boer, 1992; Lord, 1991).

All participants were first contacted by telephone by someone in the Centre's network who knew them. If the person expressed interest, he or she was then phoned by a researcher, who explained the study in more depth and obtained preliminary consent. A letter was then sent to research participants describing the study, including a commitment to ensure confidentiality. At the first meeting between the researcher and the participant, each participant was asked to sign a letter of consent.

\section{Participants}

Key informants. Eight key informants, four women and four men, came from several different areas such as the disability movement, the health promotion field, and human services. All the key informants were people with a vast array of experience and leadership who were assumed to have a strong sense of the meaning of personal empowerment. The ideas expressed by these individuals were used to assist the researchers in sorting out issues and concepts related to empowerment. Key informants also helped to identify the research participants for the biographical interviews.

People experiencing powerlessness. The researchers conducted in-depth biographical interviews with 24 women and 17 men. Participants were selected from five main groups: individuals with developmental handicaps from three communities $(n=12)$; individuals with physical disabilities from birth from four communities $(n=10)$; individuals with physical disabilities acquired later in life from two communities $(n=5)$; individuals from two communities who were consumers/survivors of mental health services $(n=6)$; and women from three communities who were identified as having been poor and disempowered, but are now 
involved in a process of empowerment $(n=8)$. In the disability groups, men and women were divided equally and ranged in age from 21 to 67 , with the average age being 42 . Most of the individuals in the disability groups had lived in an institutional setting for part of their lives. At the time of the study, everyone with a disability was living in the community, either in small group homes, on their own, or with a friend or partner and more than half were employed. None of the participants were members of visible minorities.

Focus groups. Four small focus group interviews were conducted with 14 (eight women and six men) additional people with disabilities, all of whom were chosen in the same way as the original group. They were interviewed to gain their reflections on the preliminary research patterns and themes from the biographical interviews. This group process verified and strengthened our initial findings.

\section{Data Collection}

The frameworks of qualitative research and biographical analysis were used to guide the research process. Most interviews were done in people's homes. All interviews were taped and transcribed verbatim and supplemented by field notes (Patton, 1990). Following the initial data analysis of the individual interviews, researchers returned to the field and conducted the focus group interviews.

The data were analyzed in the tradition of qualitative research. A five-step qualitative analysis process was designed to ensure that patterns and themes which might emerge from the data could be carefully verified. These included: transcribing the notes from the interviews; coding the data with key words as a way of identifying commonalities and variations; identifying common and variable patterns within each group as well as across groups; and identifying themes which link or explain the data (Patton, 1990). After the study was written, it was sent to all research participants for comments and reflections. Recently, some of the participants joined the researchers in sharing their experiences with others in educational seminars.

\section{RESULTS AND DISCUSSION}

In this section, the process of personal empowerment as described by the research participants is outlined. Common themes which emerged from the four groups of individuals will be discussed. In addition, themes which illustrate differences among the groups will be reported. As the themes are presented, the findings will be linked to the literature. This integrated approach to research reporting is considered more meaningful when working with qualitative data. The five main themes that emerged during the analysis stage were: (a) powerlessness, (b) impetus to the empowerment process, (c) support from people, (d) access to valued resources, and (e) the role of participation in community life.

\section{Powerlessness}

The research participants described in great detail the anguish of feeling powerless. No single factor or experience created a sense of powerlessness; rather, it was a build-up of factors and experiences that developed into a disempowering situation. The data showed that all four research groups experienced extended 
periods of powerlessness in their lives as a result of social isolation, unresponsive services and systems, poverty, and abuse.

Social isolation. For most of the people with disabilities, their social isolation began early in life. It was experienced at home, school, and in the community. As one young woman noted, she never went to school, "' 'cause the school wasn't accessible, so we had a teacher come in a couple days a week to teach us." As Foucault (1984) has pointed out, many groups in western culture are "'maneuvered by myths" (p. 8); one of the cruelest myths experienced by people with disabilities is that they do not have the same social needs as other citizens. For the group of low-income women, their experience of social isolation was somewhat different. Most of the women experienced very difficult childhood and/or adulthood years, and they talked extensively about the lack of support in their lives. They used terms such as neglect, isolation, and abandonment to describe their experiences. As people's lives unfolded, escaping social isolation was one of the major tasks to be undertaken on the road to empowerment.

Unresponsive services and systems. Almost all participants described the impact of service systems on their experience of powerlessness. Although many social critics have noted the problems with service systems (Galper, 1975; Illich, 1977; McKnight, 1987; Wolfensberger, 1983), the perspectives of the participants in this study helped the researchers to understand that the failure of systems is twofold: first, failure through neglect, and second, failure through inappropriate interventions. Failure through neglect was personified by the number of individuals and families who simply got "worn down" by the constant demands of dealing with poverty or disability. Failure through inappropriate interventions was often characterized by efforts that addressed the effects of problems, not the problem itself. Thus, psychiatric patients were often misdiagnosed and over-medicated, sent to more clinics, more physicians and more institutions. No one in the system recommended that these individuals seek alternative non-medical support or selfhelp that might address their real problems, issues of loneliness and powerlessness. The failure of existing services and systems to creatively address people's real problems had enormous consequences; people remained in states of prolonged dependency and the transition to empowerment was fraught with barriers.

Poverty, Poverty was a disempowering experience for all of the low-income women and for several of the participants with disabilities. Many of the women had lived on welfare for extended periods, and were forced to live in housing projects with other people who were poor. Women talked about many of their concerns: a loss of control and a perpetuation of dependency on the system, invasion of privacy, being robbed of their self-esteem, being seen as not trustworthy, being blamed for their own misfortune, and feeling oppressed. The literatures on poverty and empowerment both point to the extensive and devastating effects poverty can have on people's lives (Bremner, Crawford, Mairs, \& Minsky, 1988; Whitmore \& Kerans, 1988).

Abuse. Abuse was an important contributor to disempowerment, especially for the group of low-income women. Most of the women reported some type of abuse during childhood and/or adulthood, whether it was physical, emotional, or sexual. The abuse was inflicted on the women by a variety of people, including 
fathers, mothers, siblings, teachers, relatives, and foster parents. Besides physical abuse, the women talked about a general lack of support in their lives. Several of the women were actually left by parents or siblings as adolescents to cope on their own or find other arrangements. As a result of these situations, most of the women were forced to work at a very early age, one as young as 12 , and in some cases, this included being forced to quit school. Almost all of the women married at a very young age. The scars of the abuse remained with the women and impacted on the way they saw themselves, the way they related to men, and the way they parented their children. The few women who had stable, loving childhoods found their early positive experiences to be a sustaining factor for them during difficult times as adults. They knew life could be better and they aspired for it. For the women who were abused as children, overcoming the prolonged sense of powerlessness was continually a struggle. As one woman said: "You think scars heal. They don't . . . they hurt."

In summary, powerlessness for the research participants was both a "global" experience and a "situational" experience. As a global concept, some people experienced a sense of total powerlessness, and became, for a period, unable to see themselves as being capable of having control or being able to influence others. For these participants, this was a period in their lives of "surviving, not living." The consequences of prolonged dependency for these individuals included low self-esteem, few options, and limited experience with decision making, not dissimilar to other research and literature (Checkoway \& Norsman, 1986; Sanford \& Donovan, 1984). Most participants at this stage had very small, uninvolved social networks. The combination of social isolation and low self-esteem limited people's capacity to dream. It also affected their ability to believe in themselves and to take control of their lives. The conditions of global powerlessness experienced by these participants are similar to Goldenberg's (1978) conditions of oppression, which include containment, expendability, and compartmentalization. As a situational concept, a minority of participants experienced powerlessness only in some areas of life. These individuals were able to maintain control and self-esteem in other areas. This sense of self-efficacy became paramount for many of them later in the empowerment process.

\section{Impetus to Empowerment}

The transition toward personal empowerment was a uniquely individual and ongoing process. Charting the process required that attention be paid to each person's story, as well as to common themes across all participants. It was difficult to pinpoint exactly when the process started. Similarly, the transition to empowerment did not produce a fixed end point; few people "became empowered" and never looked back. For most of the vulnerable people who were part of this research, the process of personal empowerment was a constant struggle.

For most of the participants, their impetus to empowerment was not a conscious decision. Instead, it was motivated by some concrete factors that participants, in reflecting back, were able to identify. These factors or situations acted like catalysts for the empowerment process and led to two vital changes in participants. Individuals became aware of their own capacities and of alternatives to the experience of powerlessness. Second, individuals began to develop new 
directions for themselves. As shall be seen, these are critical elements of personal empowerment. The main fcators which participants identified as providing the impetus for change were:

- being involved in a crisis or "life transition,"

- acting on anger or frustration,

- responding to new information,

- building on inherent strengths and capabilities.

Being involved in a crisis or life transition. Kieffer (1984), in his research with community activists, found that a provocation or crisis often prompted people to become critically aware of their own situations. How the research participants dealt with crisis or life transitions varied widely. During rehabilitation, for example, people who had become disabled later in life had to come to terms with their changing life situation. The beginning of awareness was often related to questions people began to explore such as "what do I do now?" Interestingly, some people resolved this personal dilemma before they left the hospital, while others took months or years to begin to come to terms with the issue. As people gained awareness through this time, they began to realize they could still be human and still have control, despite their disability.

Crisis in our culture often has negative connotations. Yet, for many of the participants, these unsettling situations were turned into new awareness and opportunities. People who responded most favourably to crisis or life transitions were those who believed in themselves and their own abilities (self-efficacy) and people who received support from others to expand their awareness and actions (social support).

Acting on anger or frustration. As already noted, most participants had experienced extensive frustration with their life situations. Many people talked about how frustrations built up until they finally decided they could no longer accept what was happening. For several of the participants, it appeared that the drive to gain control over their lives was fueled by a combination of frustration and hope. For example, several women spoke about fighting back or standing up to someone in authority. For others, frustration which became anger led to action. Several people who became disabled later in life talked about feeling angry and frustrated with their new disability, and how these feelings motivated them to change their situation.

Anger has been defined as a strong emotion that is part of everyday life. Anger can be immobilizing or be a major force behind an individual's desire to accomplish (Lerner, 1985). Several participants had experienced years of frustration and needed outlets and opportunities in order to act on their concerns. Most of the participants did find outlets for their frustration; in fact, it appears as if the anger was a way of not giving in to fear and passivity. A minority of participants, however, explained how they became "stuck on anger" for years and were unable to move on to effective action.

Having and responding to new information. Several participants noted that new information was significant to their initial process of change. Information that was most useful included: information on rights and choices, insights into participants' own strengths, information about the people who had abused them, 
taking a course about women's issues, knowledge about appropriate resources, and learning gained from getting a formal education. This new information allowed participants to get on with their lives and begin to make a contribution to their communities, their families, and themselves.

Building on inherent strengths and capabilities. Most men and women talked about personal characteristics and qualities which contributed to their personal empowerment. Some of these included: strong values, being resourceful, determination, taking responsibility, internal strength, growing self-confidence, strong desire to improve, and hope for a better future. Interestingly, it was in retrospect that participants realized that these inherent strengths and capabilities were significant in carrying them through many difficult years. At the same time, these strengths became part of the impetus for their involvement in an empowerment process.

Consistent with other research (Kieffer, 1984; Whitmore, 1988), the empowerment process identified by these participants involved both internal characteristics and external elements. As an example of the internal, most of the research participants attributed a high degree of their own empowerment to themselves. The basis of this insight seemed to be that people understood, or perhaps learned, that they had some responsibility for their own lives.

In essence, it seems that self-motivation was an essential part of empowerment, not in any egotistical sense, but rather in terms of self-control and selfparticipation. Self-efficacy is defined as people's evaluation of their capabilities to organize and carry out activities required to attain personal goals (Bandura, 1986). In this sense, positive self-efficacy is seen as fostering confidence in ways that enhance participation and taking initiative. Personal characteristics helped people in this study to ease into the transition from powerlessness to a sense of personal control. For example, some people talked about having a drive within themselves that helped them to push for change even though life seemed desolate at times.

Developing self-efficacy was not an easy, straight-forward task. Most of the participants struggled for years without resources and often by avoiding responsibility. It was not possible to identify exactly how people came to increase their self-efficacy, but it seemed that those who believed in themselves early in the process were able to expand their empowerment quite considerably when appropriate supports and resources were made available.

\section{Support from People}

Personal supports were vital in expanding personal empowerment. Sometimes support from people was the catalyst that enabled participants to begin the journey toward more personal control. For most participants, however, the support provided by others was more useful when they had already started to become aware of alternatives. Every one of the research participants identified at least one significant person as being important to his or her personal empowerment. Participants noted that people who were most helpful played a variety of supportive roles. Three main types of support were identified as being particularly significant. 
Practical support. Many participants identified practical, tangible help that other people provided during their struggle to become more empowered. Sometimes the practical support involved providing information that enhanced the person's ability to make decisions. Typically, the practial support enabled people to solve problems. For example, one woman who had been struggling with her family while searching for a place to live, noted how her service worker helped clear up a disagreement between herself and her sister and "she also helped me find a place to live." It was interesting to speculate whether this kind of helping contributed to empowerment by doing things for the person. It seemed clear from some of the participants that many of their lives were so troubling and so lacking resources that this kind of practical help was often one of the first steps toward the person regaining a sense of control. Other times, the practical support included help in finding a job, being visited regularly during a long period of depression, and being supported to get out of an institution.

Moral support. Many participants found a person who provided important moral support. An ability to listen was the quality that was most identified as the basis of moral support. One woman noted that she had found "people who I can now talk to who have said to me 'go for it, you can do it'... I found a tremendous amount of encouragement." Sometimes the moral support came from fellow participants in a self-help group, other times from family or friends, and occasionally from a service worker. Participants often alluded to the influence of others in helping them to capture or recapture their dreams. As the experience of several participants attested, the development of a vision or sense of direction may require the support of others, but also requires that the person make use of that support to develop an internal commitment to the personal vision (Glouberman, 1989). Moral support seemed to provide people with an opportunity to confirm their own intuition, increase their belief in themselves, and recognize their own strengths and potential capacities.

Mentoring. Most of the low-income women and about one third of the participants with disabilities described a person in their lives who they perceived as a significant role model or mentor. For example, one woman talked about a social worker who encouraged and affirmed her strengths. "She wouldn't spend time focusing on my behaviour: she focused on the gifts I have and the contributions that I could make." For the most part, participants identified mentors who were of the same sex and who had been through similar experiences to themselves.

Research and analysis has suggested that "building on people's strengths" is one of the key ways to facilitate personal empowerment (Dunst, Trivette, \& Deal, 1988; Rappaport, 1987). In this way, mentoring may be a significant aspect of the empowerment process. Mentors played several roles with participants, including: believing in the person; providing appropriate information at the right time; demonstrating initiative so that the person could envision new possibilities for him or herself; and finally, challenging the person to change and participate. This research was consistent with the findings of Kieffer (1984), who found that mentors were important for individuals who were gaining a sense of empowerment through political action. 


\section{Access to Valued Resources}

An important aspect of the empowerment process was having access to valued resources. When they experienced powerlessness, most of the participants had access only to resources which they perceived as being different or specifically for "rehabilitation" or "welfare." Beginning to have access to the same valued resources and opportunities as other community members was important for people's empowerment process. For some participants, gaining employment was a pivotal point in their lives as a way of expanding their economic power. Interestingly, a job was also perceived as a way to expand other people's respect for the person. Other examples of valued resources included independent housing, technical resources such as a motorized wheelchair, and money. Parenti (1978) describes power as the ability to control powerful resources in order to get what you want, despite resistance. In a society where powerful people have wealth, property, control of jobs, prestige, and access to goods and services, people who are experiencing powerlessness have little access to these valued resources.

Interestingly, while some people spoke of services and service systems as useful, most were highly critical. When services were helpful, participants tended to mention an individual health or social service worker who was involved with them on a one-to-one basis. Participants were critial of systems which were bureaucratic, congregating, and controlling. Pinderhughes (1983) points out that too often service workers and systems see people as victims and keep people in inferior, powerless positions. These findings are consistent with social critics who have emphasized the limitations of service systems in terms of their contributions to community participation and empowerment (McKnight, 1987). Services that were of value had some common qualities, including being personalized, responsive, interactive, and providing a degree of self-reliance and consumer control. It is significant to note that the health and social service workers who were seen as helpful were characterized as "a good listener," "an equal," "'a guide," and a person "who really cares."

\section{Participation}

Participation significantly advanced the process of empowerment for all of the people involved in the research. In fact, the process of participation itself was empowering. Participants had noted their feelings of powerlessness were accompanied by a lack of participation. As people gained in self-confidence, they would seek more avenues for participation; their involvement in community activity would in turn enhance their self-confidence and sense of personal control. Explained one woman, "For the first 27 years of my life, I did no volunteer work and now I'm doing two things. It's sort of like expanding on your personal growth." The experience of participants showed that participation contributed to personal empowerment in three ways.

Reducing isolation through participation. As participants became engaged in an activity, social group, or social action, they often noted the value of the social interaction and a reduction of their social isolation. For example, a man who was hospitalized for several months noted "I made plans when I was in rehabilitation to go back to school ... I think I came to the realization, as I gained confidence, that the busier I kept myself, the better I felt." Other research has also noted that 
"getting involved" is a particularly important way for people to feel affinity with others (Bellah, Madsen, Sullivan, Swidler, \& Tipson, 1985).

Several participants talked about their experience of being invited and welcomed as being an important first step of community participation. Initial participation was usually based on personal interest which they shared with others. As people became more active and sought out avenues for their concerns and interests, they were able to take on new roles as participants, and even leaders. The literature supports this idea that in order for people to become empowered, they not only need access to valued social resources, but also to valued social roles (Wolfensberger, 1983). It appears that having an opportunity to experience a range of valued roles is empowering because it reduces isolation, increases social interaction, and enhances the person's feelings of self-worth.

Expanding participatory competence and making a contribution. Participation in community activities and associations enabled people to try new things and expand their participatory competence. A woman who joined a community group found she could open up and share of herself: "I joined the group and it was through this experience that I came out of my shell." Many participants talked about the importance of community participation for developing their skills. Several people gave examples of how having success in one aspect of their lives encouraged them to try other things. As people sustained their involvement, they deepened their competence and control. It is in this manner that participation advanced the process of personal empowerment (Kieffer, 1984).

However, not everyone expanded their confidence and competence to the same extent. For one thing, some individuals had only limited participation opportunities, while others seemed more passive about their involvement. Still others went on to play major leadership roles in community groups. Some women, for example, took the initiative to start new groups, to deal with issues that were of concern to their community. One woman noted how her analysis also broadened, "l guess being in my situation has made me aware of other minority groups in their struggles, you know, like the women's movement; I want justice for me, and anyone who has had a hard deal should be seeking or demanding justice." These women noted that they became more knowledgeable and confident as a result of their community leadership roles. This study reiterates the importance of people who have been powerless and isolated, finding ways or opportunities to contribute to their communities (Lusthaus, 1986).

Nature of participation. People in the study participated in an extremely diverse range of community groups and activities, ranging from recreation and cultural interests, mutual support and self-help, housing groups, advocacy groups, community services, environmental activities, activities for their chilren, and municipal affairs. Regardless of the nature of their participation, being part of a group and/or making a contribution to the community was important for all participants at some point in their journey. It seems that the collective experience affords a level of trust and comfort with others and a vehicle for asserting oneself (Watt \& Rodmell, 1988). Involvement was based on the person's capacity at that time and his or her commitment to the group's goals. While the types of groups and organizations varied widely, the important point was that people became more socially active over time. 


\section{Summary}

This study has contributed toward a better understanding of empowerment as a process. As a summary, Table 1 highlights the elements identified through this current study.

In addition to these five main themes related to the process of empowerment which were presented in the findings, research participants reported having a broad range of personal changes and outcomes as a result of the empowerment process. Some outcomes were in terms of their own feelings toward themselves, such as increased self-esteem, a sense that their opinions counted and that they were valued, and pride in themselves and their accomplishments. Some changes related to their relationships with others, such as being a better parent; having more equal relationships; and being more empathic, understanding, and accepting of others. Some of the changes were more in terms of their skills, such as knowing how to access valued resources, having more political skills nd knowledge, and displaying leadership skills in community groups. Still others were related to their overall life such as having more control over their personal lives, more influence in decisions regarding themselves and others, more participation in community life, and more feelings of empowerment. These varied outcomes were mentioned by participants throughout the discussion related to the process of empowerment.

\section{CONCLUSIONS}

\section{Implications for Theory and Concept}

The concept of empowerment has diverse meanings. While this study focused on the process of empowerment, there are also some important insights from this work that can contribute to clarifying the concept and meaning of empowerment. There are three areas in particular that illustrate these contributions. First, there is the interpretation of personal control. Most of the literature associates empowerment with personal control (Rappaport, 1987). The people interviewed in this study echoed this concern for control as they described their

TABLE 1

Elements of the Personal Empowerment Process*

\begin{tabular}{|c|c|c|c|c|}
\hline $\begin{array}{l}\text { Experiencing } \\
\text { Powerlessness }\end{array}$ & $\begin{array}{l}\text { Gaining } \\
\text { Awareness }\end{array}$ & $\begin{array}{l}\text { Learning } \\
\text { New Roles }\end{array}$ & $\begin{array}{l}\text { Initiating/ } \\
\text { Participating }\end{array}$ & Contributing \\
\hline social isolation & $\begin{array}{l}\text { acting on } \\
\text { anger }\end{array}$ & $\begin{array}{l}\text { connecting } \\
\text { with others }\end{array}$ & joining groups & $\begin{array}{l}\text { being a } \\
\text { role model }\end{array}$ \\
\hline $\begin{array}{l}\text { service } \\
\text { dependency }\end{array}$ & $\begin{array}{l}\text { responding } \\
\text { to information }\end{array}$ & $\begin{array}{l}\text { linking with } \\
\text { resources }\end{array}$ & speaking out & $\begin{array}{l}\text { having } \\
\text { influence }\end{array}$ \\
\hline limited choices & $\begin{array}{l}\text { responding to } \\
\text { new contexts }\end{array}$ & $\begin{array}{l}\text { expanding } \\
\text { choices! } \\
\text { opportunities }\end{array}$ & $\begin{array}{l}\text { expanding } \\
\text { participatory } \\
\text { competence }\end{array}$ & $\begin{array}{l}\text { increasing } \\
\text { self-efficacy }\end{array}$ \\
\hline
\end{tabular}

- From Lord (1991). 
struggles. Other literature describes control in terms of coping (Epp, 1986; World Health Organization, 1986). These research data strongly suggest that personal control is more than just coping. In fact, people who achieved the greatest degree of control in their lives were those who refused to accept their situation and instead kept questioning and searching for options. People had dreams and acted on them. In terms of empowerment, then, personal control can be seen as an active process of engagement in the social world. As discussed elsewhere, this insight has important implications for community health professionals (Lord \& McKillop Farlow, 1990).

Second, there has been little discussion in the empowerment literature about the relationship between empowerment and self-efficacy (Bandura, 1986). While people in this study attributed much of their empowerment to external resources and people support, they also attributed much of their change to themselves. For example, some people talked about how they had always felt assertive, but that it took a certain kind of support to bring out their assertiveness. People's belief in their own capabilities and unique personal characteristics helped foster confidence in their ability to take initiative in changing their lives. This ability to take at least some of the credit for their empowerment process contributed to increased self-esteem that may not have been otherwise possible. Interestingly, knowing and relying on others for support did not detract from people's ability to take responsibility for their future. In this sense, interdependence can be seen as an important part of the empowerment process. As the theory of empowerment becomes more fully developed, it will need to be based partly on the interaction of internal motivations with valued social resources in communities and systems.

Third, this study confirms the importance of describing empowerment in ecological terms. None of the participants became empowerd on their own. Rather, social context and community life were critical to understanding the changes that individuals experienced over time. For example, participation for study participants meant involvement in community organizations, self-help groups, and other aspects of community life. In this sense, community empowerment refers to community settings which welcome people and thus contribute to their personal empowerment. The literature has tended to separate out the concept of personal empowerment from the concept of community or group empowerment (Labonté, 1989; Wallerstein, 1992). In this study, personal empowerment always occurred in the context of community, thus illustrating the dilemma in separating out the two.

While several important learnings about the concept of empowerment have emerged from this study, continued work on concept clarification is needed. Without careful attention being paid to the concept and its meanings, there is a danger of a "technique trap," whereby a new idea is practiced without understanding. Conceptual work will thus be central to an understanding of empowerment, and will work in relationship with empirical and phenomenological research.

This research has also identified a number of elements which contributed to the process of empowerment. To be more fully understood, each of these elements could benefit from further research. As an example, mentoring was identified as a critical people support. Since little is known about the mentoring 
process, research could examine a variety of contexts in which mentoring has occurred and its relationship to empowerment. Similarly, the issues of race and culture were not a focus of this study, but the experiences of aboriginal people and citizens with other ethnic backgrounds would broaden our understanding of the empowerment process.

\section{Implications for Practice}

The research presented here in many ways reflects a substantial criticism of many common practices. Research participants' experiences showed the process

\section{TABIE 2}

\section{Empowerment Principles for Community Practice}

1. In order to understand empowerment, citizens who are devalued must be seen as oppressed and marginalized by society, not simply as clients to be served. Sources of oppression range from poverty and abuse to social isolation and lack of access to valued resources.

2. Service systems must give up their control over people who are currently devalued. This means eliminating the power relationships which exist between professionals and citizens by ensuring collaboration and by supporting consumer-controlled initiatives.

3. For a power transfer to occur, citizens must be the ones to identify the problems and solutions to personal and community issues and must have direct access to funding that normally only goes to service agencies.

4. While power cannot be given to people by professionals, concerned professionals can work to eliminate the systematic barriers that have been created which oppress, control, and disempower vulnerable citizens.

5. Listening to the concerns, stories, feelings, experiences, and hopes of people who feel powerless is the basis for broadening people's awareness of their oppression. The language of professionalism, which encourages dependency and control, needs to be replaced by dialogue, which supports mutuality and reciprocity.

6. Build upon the strengths and capacities of citizens and avoid a focus on deficits. This is critical for building self-esteem, which is both an outcome and part of the empowerment process.

7. Participation in community life at three levels is critical for the empowerment of individuals: working on issues which affect their own lives, connecting with others who have had similar experiences, and being involved in a range of community groups and activities.

8. Encourage and support citizens to make ongoing contributions to their communities through access to valued social roles such as employee, volunteer, mentor, advocate, or friend.

9. Citizens who are consumers of services should have control over the resources and personal supports they need to live with dignity.

10. It is possible to learn important strategies about prevention from studying the process of empowerment; for example, as people become more empowered, they rely less on formal service systems and more on informal support networks. These learnings can be used as important principles for proactively empowering potentially vulnerable individuals and groups. 
of becoming more empowered involves continual struggle against systems that label, reject, and segregate people. It is clear that "more of the same" will seldom contribute to empowerment. The results of this study point to a set of empowerment principles for community practice, Others have also noted principles for practice that can be empowering (Dunst, 1990; Labonté, 1990; Rose \& Black, 1985; Whitmore, 1988). The principles for practice presented in Table 2 are based on research on the lived experience of vulnerable citizens who have struggled with the process of empowerment. It is important to remember that these principles work in concert with each other; no one principle by itself will have enough impact to empower individuals and groups.

\section{RÉSUMÉ}

Cet article présente une étude réalisée sur le thème du processus d'appropriation du pouvoir (empowerment). Des entrevues qualitatives et des focus groups ont été réalisés auprès de 55 homes et femmes ayant vécu une situation d'impuissance extensive dans leur vie, dans le but de mieux comprendre leur expérience vécue dans les efforts déployés pour augmenter leur contrôle sur leurs conditions de vie. Plusieurs thèmes ont été identifiés, incluant des éléments ayant joué un rôle moteur dans le contrôle accru sur leur vie et l'importance du support provenant des autres. Tout au long du processus de développement de l'appropriation du pouvoir, l'accès à des ressources valorisces et la participation á la vie de la communauté ont diminué l'isolement et contribué à une confidence en soi et un sentiment de compétence accrus chez les participants. Plusieurs implications du concept d'appropriation du pouvoir sont ensuite dégagées, comme les notions de contrôle personnel et d'efficacité personnelle; des principes utiles à la pratique communautaires sont aussi soulignés. Cette recherche confirme l'importance de comprendre l'appropriation du pouvoir en la situant dans le cadre d'une perspective écologique.

\section{REFERENCES}

Albee, G. (1981). Politics, power, prevention and social change. In J. Joffe \& G. Albee (Eds.), Prevention through political action and social change (pp. 5-25). Hanover, NH: University Press of New England.

Asch, A. (1986). Will populism empower the disabled? Social Policy, 16(3), 12-18.

Bandura, A. (1986). Social foundations of thought and action. Englewood Cliffs, NJ: Prentice Hall.

Bellah, R., Madsen, R., Sullivan, W., Swidler, A, \& Tipton, S. (1985). Habits of the heart. New York: Harper \& Row.

Bremner, J., Crawford, N., Mairs, B., \& Minsky, E. (1988). Action on health barriers: Health promotion with low income women. Toronto: Opportunities for Advancement.

Checkoway, B., \& Norsman, A. (1986). Empowering citizens with disabilities. Community Development Journal, 21(4), 270-277.

Cochran, M. (1986). The parental empowerment process: Building on family strengths. In J. Harris (Ed.), Child psychology in action: Linking research and practice (pp, 12-33). Brookline, MA: Croon Helm.

Cornell Empowerment Group. (1989, October). Empowerment and family support. Networking Bulletin, I(1), 2.

de Boer, M. (1992). Women and empowerment. Unpublished master's thesis, School of Social Work, Wilfrid Laurier University, Waterloo, ON. 
Dunst, C.J. (1990). Family support principles: Checklists for program builders and practitioners, Family systems intervention monograph, 2(5). Morganton, NC: Family Infant and Preschool Program, Western Carolina Center.

Dunst, C., Trivette, C.M., \& Deal, A.G. (1988). Enabling and empowering families: Principles and guidelines for practice. Cambridge, MA: Brookline Books.

Edelman, M. (1977). Political language: Words that succeed and policies that fail. New York: Academic Press.

Epp. J. (1986). Achieving health for all: A framework for health promotion. Ottawa: Minister for Supply and Services.

Foucault, M. (1984). The Foucault reader. New York: Pantheon Books.

Galbraith, J.K. (1983). The anatomy of power. Boston: Houghton Mifflin.

Galper, J. (1975). The politics of social services. Englewood Cliffs, NJ: Prentice-Hall.

Glouberman, D. (1989). Life choices and life changes through imagework: The arl of developing personal vision. London: Unwin Paperbacks.

Goldenberg, 1. (1978). Oppression and social intervention: Essays on the human condition and the problems of change. Chicago, IL: Nelson-Hall.

Guba, E., \& Lincoln, Y. (1989). Fourth generation evaluation. Newberry Park, CA: Sage.

Illich, I. (1977). Disabling professions, London: Marion Boyers.

Kieffer, C. (1984). Citizen empowerment: A developmental perspective. Prevention in Human Services, 3(16), 9-35.

Labonté, R. (1989). Community empowerment: The need for political analysis. Canadian Journal of Public Health, $80(2), 87-88$,

Labonté, R. (1990). Empowerment: Notes on professional and community dimensions. Canadian Review of Social Policy, 26, 64-75.

Lerner, H.G. (1985). The dance of anger. New York: Harper \& Row.

Lerner, M. (1986). Surplus powerlessness. Oakland, CA: Institute for Labor and Mental Health.

Lord, J. (1991). Lives in transition: The process of personal empowerment. Kitchener, ON: Centre for Research and Education in Human Services.

Lord, J., \& McKillop Farlow, D. (1990). A study of personal empowerment: Implications for health promotion. Health Promotion, 29(2), 2-8.

Lord, J., Schnarr, A., \& Hutchison, P. (1987). The voice of the people: Qualitative research and the needs of consumers. Canadian Journal of Community Mental Health, $6(2), 25-36$.

Lusthaus, E. (1986). Making a contribution: An emerging social role for persons with a mental handicap. Entourage, $I(2), 24-31$.

MeKnight, J. (1987). Regenerating community. Social Policy, 17(3), 54-58.

McClelland, D.C. (1975). Power: The inner experience. New York: Irvington Press.

Miles, \& Huberman. (1984). Qualitative data analysis. Beverly Hills, CA: Sage.

Moscovitch, A., \& Drover, G. (1981). Inequality: Essays on the political economy of social welfare. Toronto: University of Toronto Press,

Parenti, M. (1978), Power and the powerless. New York: St. Martin's Press,

Patton, M. (1990). Qualitative evaluation and research methods. Beverly Hills: Sage.

Pinderhughes, E. (1983). Empowerment for our clients and for ourselves. Social Casework: The Journal of Contemporary Social Work, 64(6), 331-338.

Presby, J., Wandersman, A., Florin, P., Rich, R., \& Chavis, D. (1990). Benefits, costs, incentive management and participation in voluntary organizations: A means to understanding and promoting empowerment. American Journal of Community Psychology, $18(1), 117-148$.

Rappaport, J. (1986). Collaborating for empowerment: Creating the language of mutual help. In H. Boyte \& F. Reissman (Eds.), The new populism: The politics of empowerment (pp. 64-59). Philadephia: Temple University Press.

Rappaport, J. (1987). Terms of empowerment/exemplars of prevention: Toward a theory 
for community psychology. American Journal of Community Psychology, 15(2), 121-148.

Rose, S., \& Black, B. (1985). Advocacy and empowerment: Mental health care in the community. Boston: Routledge \& Kegan Paul.

Sanford, L., \& Donovan, M. (1984). Women and self-esteem: Understanding and improving the way we think and feel about ourselves. New York: Penguin.

Wallerstein, N. (1992). Powerlessness, empowerment and health: Implications for health promotion programs. American Journal of Health Promotion, 6(3), 197-205.

Watt, A., \& Rodmell, S. (1988), Community involvement in health promotion: Progress or panacea? Health Promotion, 2(4), 359-367.

Whitmore, E. (1988). Empowerment and the process of inquiry. A paper presented the annual meeting of the Canadian Association of Schools of Social Work, Windsor, ON.

Whitmore, E., \& Kerans, P. (1988). Participation, empowerment and welfare. Canadian Review of Social Policy, 22, 51-60.

Wolfensberger, W. (1983). Social role valorization: A proposed new term for the principle of normalization. Mental Retardation, 21 (6), 235-239.

World Health Organization, Health and Welfare Canada, Canadian Public Health Organization. (1986, November). Ottawa Charter for Health Promotion. Proceedings from the International Conference on Health Promotion, Ottawa. 